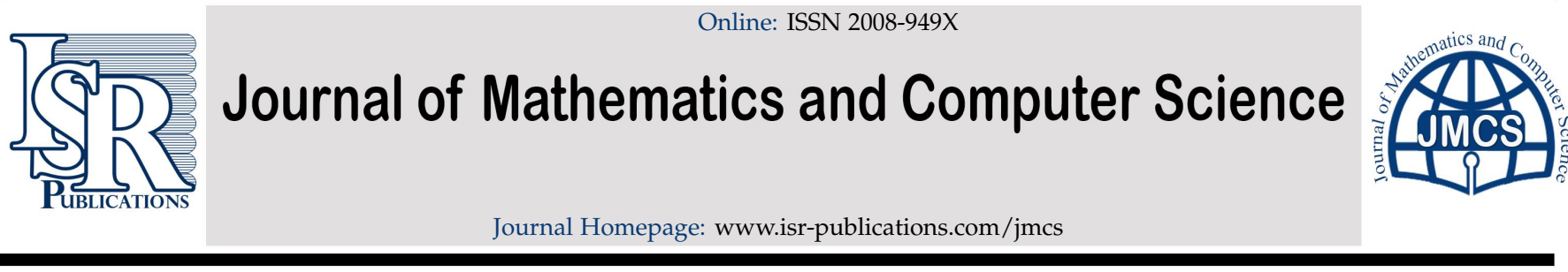

\title{
The weight inequalities on Reich type theorem in b-metric spaces
}

\author{
Zoran D. Mitrovića , Hassen Aydi ${ }^{b}$, Mohd Salmi Md Nooranic, Haitham Qawaqneh",* \\ ${ }^{a}$ Nonlinear Analysis Research Group, Ton Duc Thang University, Ho Chi Minh City, Vietnam. \\ ${ }^{b}$ Department of Mathematics, College of Education in Jubail, Imam Abdulrahman Bin Faisal University, P. O. 12020, Industrial Jubail \\ 31961, Saudi Arabia. \\ 'School of mathematical Sciences, Faculty of Science and Technology, Universiti Kebangsaan Malaysia, 43600 UKM, Selangor Darul \\ Ehsan, Malaysia.
}

\begin{abstract}
In this note, we give a generalization of the Reich type theorem in b-metric spaces by using weight inequalities. Here, the existence of nonunique fixed points is ensured. Other known fixed point results in the literature are derived.
\end{abstract}

Keywords: Fixed point, b-metric space, weight inequalities.

2010 MSC: 47H10, 54H25.

(C)2019 All rights reserved.

\section{Introduction and preliminaries}

Bakhtin [6] and Czerwik [9] introduced the notion of b-metric spaces and proved some fixed point theorems in b-metric spaces. A large number of results in fixed point theory in b-metric spaces and other generalized metric spaces has been obtained over the past ten years. For more details, see $[1,3-5,11,17-$ $22,24]$. We begin with two known definitions.

Definition 1.1. Let $X$ be a nonempty set and let $b \geqslant 1$ be a given real number. A function $d: X \times X \rightarrow[0, \infty)$ is said to be a $b$-metric if and only if for all $x, y, z \in X$, the following conditions are satisfied:

(1) $d(x, y)=0$ if and only if $x=y$;

(2) $d(x, y)=d(y, x)$;

(3) $d(x, z) \leqslant b[d(x, y)+d(y, z)]$.

\footnotetext{
*Corresponding author

Email addresses: zoran.mitrovic@tdtu.edu.vn (Zoran D. Mitrović), hmaydi@iau.edu.sa (Hassen Aydi), msn@ukm.my (Mohd Salmi Md Noorani), haitham.math77@gmail.com (Haitham Qawaqneh)
}

doi: 10.22436/jmcs.019.01.07

Received: 2018-12-08 Revised: 2019-02-14 Accepted: 2019-02-20 
A triplet $(X, d, b)$, is called a $b$-metric space.

Note that a metric space is included in the class of b-metric spaces. The topological notions of a convergent sequence, a Cauchy sequence and a complete space are defined as in metric spaces.

Definition 1.2. Let $(X, d, b)$ be a b-metric space, $\left\{x_{n}\right\}$ be a sequence in $X$ and $x \in X$.

(a) The sequence $\left\{x_{n}\right\}$ is said to be convergent in $(X, d, b)$ to $x$, if for every $\varepsilon>0$ there exists $n_{0} \in \mathbb{N}$ such that $d\left(x_{n}, x\right)<\varepsilon$ for all $n>n_{0}$. This fact is represented by $\lim _{n \rightarrow \infty} x_{n}=x$ or $x_{n} \rightarrow x$ as $n \rightarrow \infty$.

(b) The sequence $\left\{x_{n}\right\}$ is said to be Cauchy in $(X, d, b)$, if for every $\varepsilon>0$ there exists $n_{0} \in \mathbb{N}$ such that $d\left(x_{n}, x_{n+p}\right)<\varepsilon$ for all $n>n_{0}, p>0$.

(c) $(X, d, b)$ is said to be complete, if every Cauchy sequence in $X$ converges to some $X \in X$.

In this paper, we use the following result of Miculescu and Mihail [15, Lemma 2.2] and Suzuki [27, Lemma 6].

Lemma 1.3. Let $(X, d, b)$ be a b-metric space and let $\left\{x_{n}\right\}$ be a sequence in $X$. Assume that there exists $\gamma \in[0,1)$ satisfying $\mathrm{d}\left(\mathrm{x}_{\mathrm{n}+1}, \mathrm{x}_{\mathrm{n}}\right) \leqslant \gamma \mathrm{d}\left(\mathrm{x}_{\mathrm{n}}, \mathrm{x}_{\mathrm{n}-1}\right)$ for any $\mathrm{n} \in \mathbb{N}$. Then $\left\{\mathrm{x}_{\mathrm{n}}\right\}$ is Cauchy.

\section{Main results}

Definition 2.1. In the framework of a b-metric space $(X, d, b)$, a mapping $T: X \rightarrow X$ is called an $(r, a)$ weight type contraction, if there exists $\lambda \in[0,1)$ and such that

$$
d(T x, T y) \leqslant \lambda M^{r}(T, x, y, a)
$$

where $r \geqslant 0, a=\left(a_{1}, a_{2}, a_{3}\right), a_{i} \geqslant 0, i=1,2,3$ such that $a_{1}+a_{2}+a_{3}=1$ and

$$
M^{r}(T, x, y, a)= \begin{cases}{\left[a_{1}(d(x, y))^{r}+a_{2}(d(x, T x))^{r}+a_{3}(d(y, T y))^{r}\right]^{1 / r},} & r>0, \\ (d(x, y))^{a_{1}}(d(x, T x))^{a_{2}}(d(y, T y))^{a_{3},} & r=0,\end{cases}
$$

for all $x, y \in X \backslash \operatorname{Fix}(T)$, where $\operatorname{Fix}(T)=\{u \in X, T u=u\}$.

Remark 2.2. In all following cases, the $x, y \in X$ are such that $x, y \notin F i x(T)$.

1. If $r=1, a=\left(\frac{1}{3}, \frac{1}{3}, \frac{1}{3}\right)$, we obtain Reich-Rus-Ćirić type contraction,

$$
d(T x, T y) \leqslant \frac{\lambda}{3}[d(x, y)+d(x, T x)+d(y, T y)],
$$

where $\lambda \in[0,1)$, see $[8,23,25]$.

2. 1 . If $r=2, a=\left(\frac{1}{3}, \frac{1}{3}, \frac{1}{3}\right)$, we obtain the following condition,

$$
d(T x, T y) \leqslant \frac{\lambda}{\sqrt{3}}\left[d^{2}(x, y)+d^{2}(x, T x)+d^{2}(y, T y)\right]^{1 / 2},
$$

where $\lambda \in[0,1)$.

3. If $r=1$ and $a=\left(a_{1}, a_{2}, a_{3}\right)$, we have a Reich type contraction,

$$
d(T x, T y) \leqslant \alpha d(x, y)+\beta d(x, T x)+\gamma d(y, T y)],
$$

where $\alpha=\lambda a_{1}, \beta=\lambda a_{2}, \gamma=\lambda a_{3}, \alpha, \beta, \gamma, \lambda \in[0,1)$ and $\alpha+\beta+\gamma<1$, see [23].

4. If $r=1$ and $a=\left(0, \frac{1}{2}, \frac{1}{2}\right)$, we have a Kannan type contraction,

$$
d(T x, T y) \leqslant \frac{\lambda}{2}[d(x, T x)+d(y, T y)]
$$


see [14].

5. If $r=2$ and $a=\left(0, \frac{1}{2}, \frac{1}{2}\right)$, we have

$$
d(T x, T y) \leqslant \frac{\lambda}{\sqrt{2}}\left[d^{2}(x, T x)+d^{2}(y, T y)\right]^{1 / 2}
$$

6. If $r=0$ and $a=(0, \alpha, 1-\alpha)$ with $\alpha \in(0,1)$, we obtain an interpolative Kannan type contraction,

$$
d(T x, T y) \leqslant \lambda(d(x, T x))^{\alpha}(d(y, T y))^{1-\alpha},
$$

see [12].

7. If $r=0$ and $a=(\beta, \alpha, 1-\alpha-\beta)$ with $\alpha, \beta \in(0,1)$, we have an interpolative Reich-Rus-Ćirić type contraction,

$$
d(T x, T y) \leqslant \lambda(d(x, y))^{\beta}(d(x, T x))^{\alpha}(d(y, T y))^{1-\alpha-\beta},
$$

see [13].

Lemma 2.3. If $r \leqslant s$, then we have the following weighted inequality:

$$
M^{r}(T, x, y, a) \leqslant M^{s}(T, x, y, a) .
$$

Proof. See for example [7].

Our essential main result is

Theorem 2.4. Let $(\mathrm{X}, \mathrm{d}, \mathrm{b})$ be a complete $\mathrm{b}$-metric space and $\mathrm{T}: \mathrm{X} \rightarrow \mathrm{X}$ be an $(\mathrm{r}, \mathrm{a})$-weight type contraction mapping. Then $T$ has a fixed point $x^{*} \in X$ and for any $x_{0} \in X$ the sequence $\left\{T^{n} x_{0}\right\}$ converges to $x^{*}$ if one of the following conditions holds:

(i) T is continuous at such point $x^{*}$;

(ii) $b^{r} a_{2}<1$;

(iii) $b^{r} a_{3}<1$.

Proof. Let $x_{0} \in X$ be arbitrary. Define the sequence $\left\{x_{n}\right\}$ by $x_{n+1}=T x_{n}$ for all $n \geqslant 0$. If there exists $n_{0}$ such that $x_{n_{0}}=x_{n_{0}+1}$, then $x_{n_{0}}$ is a fixed point of $T$. The proof is completed. From now, assume that $x_{n} \neq x_{n+1}$ for all $n \geqslant 0$.

1. Case $r>0$. From condition (2.1), we have that

$$
d\left(x_{n+1}, x_{n}\right) \leqslant \lambda\left[a_{1}\left(d\left(x_{n}, x_{n-1}\right)\right)^{r}+a_{2}\left(d\left(x_{n}, x_{n+1}\right)\right)^{r}+a_{3}\left(d\left(x_{n-1}, x_{n}\right)\right)^{r}\right]^{1 / r} .
$$

Therefore,

$$
d\left(x_{n+1}, x_{n}\right) \leqslant\left[\frac{\lambda^{r}\left(a_{1}+a_{3}\right)}{1-\lambda^{r} a_{2}}\right]^{1 / r} d\left(x_{n}, x_{n-1}\right) .
$$

Put $\gamma=\left[\frac{\lambda^{r}\left(a_{1}+a_{3}\right)}{1-\lambda^{r} a_{2}}\right]^{1 / r}$. We have that $\gamma \in[0,1)$. It follows from Lemma 1.3 that $\left\{x_{n}\right\}$ is a Cauchy sequence in $X$. By completeness of $(X, d, b)$, there exists $x^{*} \in X$ such that

$$
\lim _{n \rightarrow \infty} x_{n}=x^{*} .
$$

Now, we claim that $x^{*}$ is a fixed point of $T$. First, for any $n \in \mathbb{N}$, we have

$$
d\left(x^{*}, T x^{*}\right) \leqslant b\left[d\left(x^{*}, x_{n+1}\right)+d\left(T x_{n}, T x^{*}\right)\right] .
$$


(i) Suppose that $T$ is a continuous map at the point $x^{*} \in X$.

Since $\lim _{n \rightarrow \infty} d\left(x^{*}, x_{n+1}\right)=0$ and $T$ is a continuous at a point $x^{*}$, we have

$$
\lim _{n \rightarrow \infty} d\left(T x_{n}, T x^{*}\right)=d\left(T x^{*}, T x^{*}\right)=0,
$$

and from (2.3), we obtain $d\left(x^{*}, T x^{*}\right)=0$, i.e., $T x^{*}=x^{*}$.

(ii) Suppose that $b^{r} a_{2}<1$. Assume that $T x^{*} \neq x^{*}$. We have

$$
\begin{aligned}
0<d\left(T x^{*}, x^{*}\right) \leqslant & b\left[d\left(T x^{*}, x_{n+1}\right)+d\left(x_{n+1}, x^{*}\right)\right] \\
= & b\left[d\left(T x^{*}, T x_{n}\right)+d\left(x_{n+1}, x^{*}\right)\right] \\
\leqslant & b\left[a_{1} d\left(\left(x^{*}, x_{n}\right)\right)^{r}+a_{2}\left(d\left(x^{*}, T x^{*}\right)\right)^{r}+a_{3}\left(d\left(x_{n}, x_{n+1}\right)\right)^{r}\right]^{1 / r} \\
& +b d\left(x_{n+1}, x^{*}\right) .
\end{aligned}
$$

At the limit as $n \rightarrow \infty$, we have

$$
0<d\left(T x^{*}, x^{*}\right) \leqslant b a_{2}^{1 / r} d\left(T x^{*}, x^{*}\right) .
$$

Since $\mathrm{ba}_{2}^{1 / \mathrm{r}}<1$, we have a contradiction, that is, $T x^{*}=x^{*}$.

(iii) Suppose that $b^{r} a_{3}<1$. Again, assume that $d\left(T x^{*}, x^{*}\right)>0$. Then

$$
\begin{aligned}
0<d\left(x^{*}, T x^{*}\right) \leqslant & b\left[d\left(x^{*}, x_{n+1}\right)+d\left(x_{n+1}, T x^{*}\right)\right] \\
= & b\left[d\left(x^{*}, x_{n+1}\right)+d\left(T x_{n}, T x^{*}\right)\right] \\
\leqslant & b d\left(x^{*}, x_{n+1}\right)+b\left[a_{1}\left(d\left(x_{n}, x^{*}\right)\right)^{r}+a_{2}\left(d\left(x_{n}, x_{n+1}\right)\right)^{r}\right. \\
& \left.+a_{3}\left(d\left(x^{*}, T x^{*}\right)\right)^{r}\right]^{1 / r} .
\end{aligned}
$$

Taking $\mathrm{n} \rightarrow \infty$, we have

$$
0<d\left(T x^{*}, x^{*}\right) \leqslant b a_{3}^{1 / r} d\left(T x^{*}, x^{*}\right) .
$$

Since $\mathrm{ba}_{3}^{1 / \mathrm{r}}<1$, we get a contradiction. Thus, $T x^{*}=x^{*}$.

2. Case $r=0$. Here, (2.1) and (2.2) become

$$
d(T x, T y) \leqslant \lambda(d(x, y))^{a_{1}}(d(x, T x))^{a_{2}}(d(y, T y))^{1-a_{1}-a_{2},}
$$

for all $x, y \in X \backslash F i x(T)$, where $\lambda \in[0,1)$ and $a_{1}, a_{2} \in(0,1)$. Following [13, Theorem 2.1 with its metric case], the map T has a fixed point in X. Again, following [13, Example 2.1 and Example 2.2], we have not a uniqueness of fixed points.

Remark 2.5. We note that for $r=0$, the proof follows from Lemma 2.3 and the case $r>0$.

We state the following corollaries.

Corollary 2.6. Let $(\mathrm{X}, \mathrm{d}, \mathrm{b})$ be a complete $\mathrm{b}$-metric space and $\mathrm{T}: \mathrm{X} \rightarrow \mathrm{X}$ be a mapping such that

$$
d(T x, T y) \leqslant \lambda d^{a_{1}}(x, y) \cdot d^{a_{2}}(x, T x) \cdot d^{a_{3}}(y, T y),
$$

for all $x, y \in X \backslash F i x(T)$, where $\lambda \in[0,1), a_{1}, a_{2}, a_{3} \geqslant 0$ and $a_{1}+a_{2}+a_{3}=1$. Then $T$ has a fixed point $x^{*}$ and for any $\mathrm{x}_{0} \in \mathrm{X}$ the sequence $\left\{\mathrm{T}^{\mathrm{n}} \mathrm{x}_{0}\right\}$ converges to $\mathrm{x}^{*}$.

Proof. Put in Theorem 2.4, $r=0$ and $a=\left(a_{1}, a_{2}, a_{3}\right)$.

Remark 2.7. We note that from Corollary 2.6, we get [13, Theorem 2] (for metric spaces).

Corollary 2.8. Let $(\mathrm{X}, \mathrm{d}, \mathrm{b})$ be a complete $\mathrm{b}$-metric space and $\mathrm{T}: \mathrm{X} \rightarrow \mathrm{X}$ be a mapping such that

$$
d(T x, T y) \leqslant \lambda \sqrt[3]{d(x, y) \cdot d(x, T x) \cdot d(y, T y)},
$$

for all $x, y \in X \backslash F i x(T)$, where $\lambda \in[0,1)$. Then $T$ has a fixed point $x^{*}$ and for any $x_{0} \in X$, the sequence $\left\{T^{n} x_{0}\right\}$ 
converges to $x^{*}$.

Proof. Put in Theorem 2.4, $\mathrm{r}=0$ and $\mathrm{a}=\left(\frac{1}{3}, \frac{1}{3}, \frac{1}{3}\right)$.

Corollary 2.9. Let $(\mathrm{X}, \mathrm{d}, \mathrm{b})$ be a complete $\mathrm{b}$-metric space and $\mathrm{T}: \mathrm{X} \rightarrow \mathrm{X}$ be a mapping such that

$$
d(T x, T y) \leqslant \frac{\lambda}{3}[d(x, y)+d(x, T x)+d(y, T y)]
$$

for all $x, y \in X \backslash F i x(T)$, where $\lambda \in[0,1)$, then $T$ has a fixed point $x^{*}$ and for any $x_{0} \in X$, the sequence $\left\{T^{n} x_{0}\right\}$ converges to $x^{*}$ if one of the following conditions holds:

(i) $T$ is continuous at such point $x^{*} \in X$;

(ii) $\mathrm{b}<3$.

Proof. Put in Theorem 2.4, $\mathrm{r}=1$ and $\mathrm{a}=\left(\frac{1}{3}, \frac{1}{3}, \frac{1}{3}\right)$.

Corollary 2.10. Let $(\mathrm{X}, \mathrm{d}, \mathrm{b})$ be a complete $\mathrm{b}$-metric space and $\mathrm{T}: \mathrm{X} \rightarrow \mathrm{X}$ be a mapping such that

$$
d(T x, T y) \leqslant \frac{\lambda}{\sqrt{3}}\left[d^{2}(x, y)+d^{2}(x, T x)+d^{2}(y, T y)\right]^{1 / 2},
$$

for all $x, y \in X \backslash F i x(T)$, where $\lambda \in[0,1)$, then $T$ has a fixed point $x^{*}$ and for any $x_{0} \in X$, the sequence $\left\{T^{n} x_{0}\right\}$ converges to $x^{*}$ if one of the following conditions holds:

(i) $T$ is continuous at such point $x^{*} \in X$;

(ii) $b^{2}<3$.

Proof. Put in Theorem 2.4, $\mathrm{r}=2$ and $\mathrm{a}=\left(\frac{1}{3}, \frac{1}{3}, \frac{1}{3}\right)$.

Theorem 2.4 is illustrated by the following examples.

Example 2.11. Let $X=\{0,1,2,4\}$ be a set endowed with the classical metric $d(x, y)=|x-y|(b=1)$, that is,

\begin{tabular}{|c|c|c|c|c|}
\hline$d(x, y)$ & 0 & 1 & 2 & 4 \\
\hline 0 & 0 & 1 & 2 & 4 \\
\hline 1 & 1 & 0 & 1 & 3 \\
\hline 2 & 2 & 1 & 0 & 2 \\
\hline 4 & 4 & 3 & 2 & 0 \\
\hline
\end{tabular}

We define a self-mapping $\mathrm{T}$ on $\mathrm{X}$ by $\mathrm{T}:\left(\begin{array}{llll}0 & 1 & 2 & 4 \\ 2 & 4 & 2 & 4\end{array}\right)$. It is clear that $\mathrm{T}$ is not a Reich-Rus-Ćirić contraction. Indeed, there is no $\lambda \in[0,1)$ such that the following inequality is fulfilled

$$
d(T 0, T 1) \leqslant \frac{\lambda}{3}[d(0,1)+d(0, T 0)+d(1, T 1)]
$$

namely, we have,

$$
2 \leqslant \frac{\lambda}{3}[1+2+3]
$$

So, we can not apply Corollary 2.9.

Also, from condition (2.4) we obtain

$$
d(T 0, T 1) \leqslant \lambda \sqrt[3]{d(0,1) \cdot d(0, T 0) \cdot d(1, T 1)},
$$


i.e., $2 \leqslant \lambda \sqrt[3]{1 \cdot 2 \cdot 3}$, so $\lambda \geqslant \frac{2}{\sqrt[3]{6}}>1$. Hence can not apply Corollary 2.8 .

On the other hand, the conditions of Corollary 2.10 are valid. Let $x, y \in X$ be such that $x, y \in X \backslash F i x(T)$. Then $x, y \in\{0,1\}$. For $\lambda=\sqrt{\frac{6}{7}}$, we have in this case,

$$
d(T x, T y) \leqslant \frac{\lambda}{\sqrt{3}}\left[d^{2}(x, y)+d^{2}(x, T x)+d^{2}(y, T y)\right]^{1 / 2},
$$

for $x, y \in\{0,1\}$ and $\lambda=\sqrt{\frac{6}{7}}$ and $\{2,4\}$ is the set of fixed points of $T$.

Example 2.12. Consider the set $X=[1,2]$. Take on $X$ the $b$-metric $d(x, y)=|x-y|^{2}(b=2)$. Obviously, $(X, d)$ is a complete $b-$ metric space. Consider now the mapping

$$
\mathrm{T} x=\frac{1+x}{2} .
$$

Let $x, y \in X$ be such that $x, y \in X \backslash F i x(T)$. Then $x, y \in(1,2]$. Showing that

$$
d(T x, T y) \leqslant \frac{\lambda}{\sqrt{3}}\left[d^{2}(x, y)+d^{2}(x, T x)+d^{2}(y, T y)\right]^{1 / 2}
$$

is equivalent to

$$
3 d^{2}(T x, T y) \leqslant \lambda^{2}\left[d^{2}(x, y)+d^{2}(x, T x)+d^{2}(y, T y)\right]
$$

that is,

$$
\frac{3}{16}|x-y|^{4} \leqslant \lambda^{2}\left[|x-y|^{4}+\frac{1}{16}|x-1|^{4}+\frac{1}{16}|x-1|^{4}\right],
$$

which holds when taking $\lambda \in\left[\frac{\sqrt{3}}{4}, 1\right)$. Note that $T$ is continuous at 1 . All the conditions of Corollary 2.10 are satisfied. Here, 1 is the fixed point of $\mathrm{T}$.

\section{Acknowledgment}

The authors thank UKM university, Malaysia since this work has been financially supported by UKM Grant DIP-2017-011 and FRGS/1/2017/STG06/UKM/01/1. We also thank the editor and reviewers for careful reading of the paper and for helpful comments, allowing us to improve our results.

\section{References}

[1] A. Aghajani, M. Abbas, J. R. Roshan, Common fixed point of generalized weak contractive mappings in partially ordered b-metric spaces, Math. Slovaca, 64 (2014), 941-960. 1

[2] H. Aydi, R. Banković, I. Mitrović, M. Nazam, Nemytzki-Edelstein-Meir-Keeler type results in b-metric spaces, Discrete Dyn. Nat. Soc., 2018 (2018), 7 pages.

[3] H. Aydi, M.-F. Bota, E. Karapinar, S. Mitrović, A fixed point theorem for set-valued quasi-contractions in b-metric spaces, Fixed Point Theory Appl., 2012 (2012), 8 pages. 1

[4] H. Aydi, M.-F. Bota, E. Karapinar, S. Moradi, A common fixed point for weak $\phi$-contractions on b-metric spaces, Fixed Point Theory, 13 (2012), 337-346.

[5] H. Aydi, A. Felhi, S. Sahmim, Common fixed points via implicit contractions on b-metric-like spaces, J. Nonlinear Sci. Appl., 10 (2017), 1524-1537. 1

[6] I. A. Bakhtin, The contraction mapping principle in quasimetric spaces, Funct. Anal. Ulianowsk Gos. Ped. Inst., 30 (1989), 26-37. 1

[7] P. S. Bullen, D. S. Mitrinović, P. M. Vasić, Means and Their Inequalities, D. Reidel Publishing Co., Dordrecht, (1988). 2

[8] L. B. Ćirić, A generalization of Banach's contraction principle, Proc. Amer. Math. Soc., 45 (1974), 267-273. 2.2

[9] S. Czerwik, Contraction mappings in b-metric spaces, Acta Math. Inform. Univ. Ostraviensis, 1 (1993), 5-11. 1

[10] M. Jovanović, Z. Kadelburg, S. Radenović, Common fixed point results in metric-type spaces, Fixed Point Theory Appl., 2010 (2010), 15 pages. 
[11] N. Hussain, Z. D. Mitrović, On multi-valued weak quasi-contractions in b-metric spaces, J. Nonlinear Sci. Appl., 10 (2017), 3815-3823. 1

[12] E. Karapinar, Revisiting the Kannan Type Contractions via Interpolation Adv. Theory, J. Nonlinear Anal. Appl., 2 (2018), 85-87. 2.2

[13] E. Karapinar, R. Agarwal, H. Aydi, Interpolative Reich-Rus-Ćirić Type Contractions on Partial Metric Spaces, Mathematics, 60 (2018), 7 pages. 2.2, 2, 2.7

[14] R. Kannan, Some results on fixed points, Bull. Calcutta Math. Soc., 60 (1968), 71-76. 2.2

[15] R. Miculescu, A. Mihail, New fixed point theorems for set-valued contractions in b-metric spaces, J. Fixed Point Theory Appl., 19 (2017), 2153-2163. 1

[16] Z. Mustafa, M. M. M. Jaradat, H. Aydi, A. Alrhayyel, Some common fixed points of six mappings on $\mathrm{G}_{\mathrm{b}}$-metric spaces using (E.A) property, Eur. J. Pure Appl. Math., 11 (2018), 90-109.

[17] H. A. Qawaqneh, M. S. M. Noorani, W. Shatanawi, Fixed Point Results for Geraghty Type Generalized F-contraction for Weak alpha-admissible Mapping in Metric-like Spaces, Eur. J. Pure Appl. Math., 11 (2018), 702-716. 1

[18] H. Qawaqneh, M. S. M. Noorani, W. Shatanawi, Fixed Point Theorems for $(\alpha, k, \theta)$-Contractive Multi-Valued Mapping in b-Metric Space and Applications, Int. J. Math. Comput. Sci., 14 (2019), 263-283.

[19] H. Qawaqneh, M. S. M. Noorani, W. Shatanawi, K. Abodayeh, H. Alsamir, Fixed point for mappings under contractive condition based on simulation functions and cyclic $(\alpha, \beta)$-admissibility, J. Math. Anal., 9 (2018), 38-51.

[20] H. Qawaqneh, M. S. M. Noorani, W. Shatanawi, H. Alsamir, Common fixed points for pairs of triangular ( $\alpha$ )-admissible mappings, J. Nonlinear Sci. Appl., 10 (2017), 6192-6204.

[21] H. Qawaqneh, M. S. M. Noorani, W. Shatanawi, H. Alsamir, Common Fixed Point Theorems for Generalized Geraghty $(\alpha, \psi, \phi)$-Quasi Contraction Type Mapping in Partially Ordered Metric-like Spaces, Axioms, 7 (2018).

[22] H. Qawaqneh, M. S. M. Noorani, W. Shatanawi, H. Aydi, H. Alsamir, Fixed Point Results for Multi-Valued Contractions in b-Metric Spaces and an Application, Mathematics, 7 (2018). 1

[23] S. Reich, Some remarks concerning contraction mappings, Canad. Math. Bull., 14 (1971), 121-124. 2.2

[24] J. R. Roshan, V. Parvaneh, Z. Kadelburg, N. Hussain, New fixed point results in rectangular b-metric spaces, Nonlinear Anal. Model. Control, 21 (2016), 614-634. 1

[25] I. A. Rus, Generalized Contractions and Applications, Cluj University Press, Clui-Napoca, (2001). 2.2

[26] S. L. Singh, S. Czerwik, K. Król, A. Singh, Coincidences and fixed points of hybrid contractions, Tamsui Oxf. J. Math. Sci., 24 (2008), 401-416.

[27] T. Suzuki, Basic inequality on a b-metric space and its applications, J. Inequal. Appl., 2017 (2017), 11 pages. 1 